\title{
Inactivation of Giardia lamblia cysts by UV irradiation in real field waters.
}

\author{
Gwy-Am Shin ${ }^{1 *}$, Karl G. Linden ${ }^{2}$, Gaetan Faubert ${ }^{3}$, and Mark D. Sobsey ${ }^{4}$ \\ 1: Department of Environmental and Occupational Health Sciences \\ University of Washington \\ Seattle, WA 98105-6099 \\ 2: Department of Civil \& Environmental Engineering \\ Duke University \\ Durham, NC 27708 \\ 3: Institute of Parasitology \\ McGill University \\ Ste. Anne-de-Bellevue, Qc, Canada H9X 3V9 \\ 4: Department of Environmental Sciences and Engineering, \\ University of North Carolina at Chapel Hill, \\ Chapel Hill, NC 27599-7400
}

\section{INTRODUCTION}

Giardia lamblia is one of the most problematic waterborne pathogens in the world. It is ubiquitous in wastewater (Sykora et al., 1991), highly prevalent in surface and source water (LeChevallier and Norton, 1995) and very resistant to conventional water and wastewater treatment processes (Gibson III et al, 1998). A properly operated conventional filtration system achieves some removal of this microorganism, but most chemical disinfection processes achieve only modest inactivation of this microorganism at practical doses and contact times (Sobsey, 1989, Clark et al., 1993, Gibson III et al, 1998). Previous studies based on the in vitro viability assays of excystation and vital dye staining suggested that $G$. lamblia cysts are very resistant to UV irradiation (Rice and Hoff, 1981). However, recent studies using in vivo animal infectivity assays indicate that low-pressure (LP) UV irradiation extensively inactivate G. lamblia cysts at relatively low doses (Linden et al, 2002, Mofidi et al, 2002, Campbell et al, 2002). In fact, the required UV doses to achieve significant inactivation of this microorganism are as low as those of enteric bacteria and far lower than those of the enteric viruses studied in previous research (Sobsey, 1989). However, most of these studies were performed in demand-free synthetic buffered waters and little has been studied in real field waters that may have quite different physical and chemical properties compared to buffered waters. Therefore, we determined the kinetics and extent of inactivation of $G$. lamblia cysts by several doses of both LP and medium pressure (MP) UV in buffered and real field waters in order to determine the effectiveness of these UV technologies in different water matrix. 


\section{MATERIALS AND METHODS}

\section{Giardia lamblia:}

G. lamblia cysts were purchased from Parasitology Research Labs, Denver, Colorado. Shed cysts collected from experimentally infected Mongolian gerbils were screened to remove large debris, then mixed with zinc sulfate solution $\left(\mathrm{ZnSO}_{4}, 1.2\right.$ specific gravity), and centrifuged at $1,500 \mathrm{rpm}$ for 5 minutes. Cysts recovered from the supernatant were washed with distilled water, resuspended in buffer solution containing antibiotics and stored at $4{ }^{\circ} \mathrm{C}$ until use.

\section{Field waters}

Filtered water samples were taken from Orange County Water and Sewer Authority (OWASA) water treatment plant, Chapel Hill, North Carolina. This facility has conventional coagulation, flocculation, and rapid dual-media (anthracite and sand) filtration units. Samples for experiments were taken just after the filtration unit. The pH's of these waters were around 8.10 with turbidity ranging from 0.09 to 0.18 .

\section{UV irradiation systems, radiometry, and dose determinations:}

Bench-scale collimated beam UV apparatus previously described (Shin et al, 2001, and Linden et al, 2002) were used in this study, and the radiometry and the target UV doses were determined in the same matter described in those literature.

\section{UV disinfection experiments:}

Five-ml volumes of phosphate-buffered saline (PBS, $\mathrm{pH} 7.3$ ) or the filtered drinking water containing purified $G$. lamblia cysts at concentrations of $\sim 10^{5}$ organisms $/ \mathrm{ml}$ in $60 \times 15 \mathrm{~mm}$ cell culture petri dishes were irradiated using UV collimated beam systems while magnetically stirring the samples slowly at room temperature $\left(23-25{ }^{\circ} \mathrm{C}\right)$. After predetermined exposure times, samples were removed from the UV irradiation systems and diluted serially 10-fold for subsequent infectivity assay.

\section{Gerbil infectivity assay and MPN calculation:}

G. lamblia infectivity assay was done in gerbils as previously described (Linden et al, 2002). The infectivity titers of G. lamblia cysts in samples were calculated as most probable number (MPN) values based on the presence and absence of cysts and trophozoites in individual gerbils that had been inoculated with sample dilutions containing specific number of cysts. The data for positive and negative animals per sample dilution and cyst concentration at each given sample dilution were used to estimate the MPN titer according to the Thomas equation. The MPN was presented as number of infectious cysts per total number of cysts doses per animal (counted by hemocytometer during each experiment). 


\section{RESULTS AND DISCUSSION}

Table 1 summarizes the raw gerbil infectivity assay data, the computed MPN, and the MPN $\log$ reductions of each experiment performed. The inactivation of G. lamblia cysts by LP UV was very rapid in both PBS and the filtered water and more than $4 \log _{10}$ inactivation was achieved within a UV dose of $1 \mathrm{~mJ} / \mathrm{cm}^{2}$ in both suspending media. Also, it appears that the extent and kinetics of inactivation of $G$. lamblia cysts by LP UV in both media were relatively similar to each other. Meanwhile, the inactivation of $G$. lamblia cysts by MP UV in the filtered water was even more rapid and reached the detection limit of gerbil infectivity assay $\left(\sim 4 \log _{10}\right)$ within a UV dose of $1 / 2 \mathrm{~mJ} / \mathrm{cm}^{2}$.

Table 1. Raw animal infectivity testing data and computed inactivation for UV disinfection of Giardia lamblia cysts

\begin{tabular}{|c|c|c|c|c|c|c|c|c|c|}
\hline $\begin{array}{l}\text { Lamp Type } \\
\text { Suspended in }\end{array}$ & $\begin{array}{l}\text { UV Dose } \\
\mathrm{mJ} / \mathrm{cm}^{2}\end{array}$ & $\begin{array}{c}\text { Cyst } \\
\text { Dose }^{1}\end{array}$ & $\begin{array}{c}\text { Infectivity } \\
\text { Response }^{2}\end{array}$ & $\begin{array}{c}\text { Cyst } \\
\text { Dose }^{1}\end{array}$ & $\begin{array}{l}\text { Infectivity } \\
\text { Response }^{2}\end{array}$ & $\begin{array}{c}\text { Cyst } \\
\text { Dose }^{1}\end{array}$ & $\begin{array}{l}\text { Infectivity } \\
\text { Response }^{2}\end{array}$ & $\begin{array}{c}\text { Infectivity } \\
\text { MPN }\end{array}$ & $\begin{array}{l}\text { Log Reduction } \\
\log _{10} N_{d} / N_{\circ}\end{array}$ \\
\hline LP & 0, Control & 5 & $0 / 4$ & 50 & $4 / 4$ & & & 60302 & \\
\hline PBS & $\begin{array}{c}0.5 \\
1\end{array}$ & 500 & $0 / 4$ & $\begin{array}{l}5000 \\
5000\end{array}$ & $\begin{array}{l}3 / 4 \\
0 / 4\end{array}$ & $\begin{array}{l}50000 \\
50000\end{array}$ & $\begin{array}{l}4 / 4 \\
1 / 4\end{array}$ & $\begin{array}{c}178 \\
5\end{array}$ & $\begin{array}{l}2.53 \\
4.07\end{array}$ \\
\hline $\begin{array}{c}\text { LP } \\
\text { Filtered water }\end{array}$ & $\begin{array}{c}\text { 0, Control } \\
0.5 \\
1\end{array}$ & $\begin{array}{c}5 \\
500\end{array}$ & $\begin{array}{l}0 / 4 \\
0 / 4\end{array}$ & $\begin{array}{c}50 \\
5000 \\
5000\end{array}$ & $\begin{array}{l}4 / 4 \\
3 / 4 \\
1 / 4\end{array}$ & $\begin{array}{l}50000 \\
50000\end{array}$ & $\begin{array}{l}3 / 4 \\
0 / 4\end{array}$ & $\begin{array}{c}60302 \\
53 \\
5\end{array}$ & $\begin{array}{l}3.05 \\
4.07\end{array}$ \\
\hline $\begin{array}{c}\text { MP } \\
\text { Filtered water }\end{array}$ & $\begin{array}{c}0 \text {, Control } \\
0.5 \\
1\end{array}$ & $\begin{array}{c}7 \\
320\end{array}$ & $\begin{array}{l}4 / 4 \\
0 / 4\end{array}$ & $\begin{array}{c}64 \\
3200 \\
3200\end{array}$ & $\begin{array}{l}4 / 4 \\
0 / 4 \\
0 / 4\end{array}$ & $\begin{array}{l}32000 \\
32000\end{array}$ & $\begin{array}{l}0 / 4 \\
2 / 4\end{array}$ & $\begin{array}{c}>188421 \\
<7 \\
20\end{array}$ & $\begin{array}{l}>4.07 \\
>3.97\end{array}$ \\
\hline
\end{tabular}

1: Cyst Dose is the number of Giardia lamblia cysts dosed into each animal

2: Infectivity Response is the number of animals with living stages of Giardia present/total number of animals infected

The results of this study support previous findings suggesting $G$. lamblia cysts are very sensitive to LP UV irradiation (Linden et al, 2002, Mofidi et al, 2002, Campbell et al, 2002). Also, this and a previous study (Mofidi et al, 2002) suggest that LP UV irradiation could be quite effective in inactivating G. lamblia cysts in various different real field waters with different physical and chemical properties. Furthermore, the results of this study indicate that MP UV irradiation is also very effective - possibly more effective - in inactivating $G$. lamblia cysts in real field waters. Meanwhile, the inactivation kinetics of G. lamblia cysts by MP UV in this study is somewhat faster than those in previous studies with G. muris (Craik et al, 2002, Belosevic et al, 2001). It is not certain at this moment if this discrepancy is due to species differences (lamblia vs. muris), different suspending media (different field waters), the purity and physical state of the cysts, UV dosimetry conditions, the variability of animal infectivity assay, or other factors. 


\section{ACKNOWLEDGMENT}

This research was supported by funds from the National Science Foundation (Project No. BES-0302609).

\section{REFERENCES}

Belosevic, M., S. A. Craik, J. L. Stafford, N. F. Norman, J. Kruithof, and D. Smith. 2001. Studies on the resistance/reactivation of Giardia muris cysts and Cryptosporidium parvum oocysts exposed to medium-pressure ultraviolet radiation. FEMS Microbiol. Letter. 204: 197-203.

Campbell, A. T. and P. Wallis. 2002. The effect of UV irradiation on human-derived Giardia lamblia cysts. Water Research. 36: 963-969.

Clark, R. M., C. J. Hurst, and S. Regli. 1993. Costs and benefits of pathogen control in drinking water. p. 181-198. In Craun, G. F. (ed.), Safety of Water Disinfection: Balancing Chemical and Microbial Risks. International Life Sciences Press, Washington, D. C.

Craik, S. A., G. R. Finch, J. R. Bolton, and M. Belosevic. 2000. Inactivation of Giardia muris cysts using medium pressure ultraviolet radiation in filtered drinking water. Water Research. 34 (18): 4325-4332.

Gibson III, C. J., C. N. Hass, and J. B. Rose. 1998. Risk assessment of waterborne protozoa: current status and future trends. Parasitology. 117 Suppl: S205-212.

LeChevallier, M. W. and W. D. Norton. 1995. Giardia and Cryptosporidium in raw and finished water. Journal of American Water Works Association. 87 (9): 54-68.

Linden, K. G., G. Shin, G. Faubert, W. Carns and M. D. Sobsey. 2002. Inactivation of Giardia lamblia cysts by low pressure UV radiation. Environmental Science and Engineering. 36(11): 2519-2522.

Mofidi, A. A., E. A. Meyer, P. M. Wallis, C. I. Chou, B. P. Meyer, S. Ramalinggam, and B. M. Coffey. 2002. The effect of UV light on the inactivation of Giardia lamblia and Giardia muris cysts as determined by animal infectivity assay (P-2951-01). Water Research. 36: 2098-2108.

Rice, E. W. and J. C. Hoff. 1981. Inactivation of Giardia lamblia cysts by ultraviolet irradiation. Applied and Environmental Microbiology. 42: 546-547.

Shin, G., K. G. Linden, M. J. Arrowood, and M. D. Sobsey. 2001. Low pressure UV inactivation and DNA repair potential of Cryptosporidium parvum oocysts. Applied and Environmental Microbiology. 67: 3029-3032. 
Sobsey, M. D. 1989. Inactivation of Health-related Microorganisms in Water by Disinfection Processes. Water Science and Technology. 21: 179-195.

Sykora J. L., C. A. Sorber, W. Jakubowski, L. W. Casson, P. D. Gavaghan, M. A. Sapiro, and M. J. Schott. 1991. Distribution of Giardia cysts in wastewater. Water Science and Technology. 24 (2): 187-192. 